\title{
Fatigue Behavior of Open-Holed CFRP Laminates with Initially Cut Fibers
}

\author{
Sudarsono ${ }^{1,2}$, Keiji Ogi $^{1}$ \\ ${ }^{1}$ Graduate School of Science and Engineering, Ehime University, Ehime, Japan \\ ${ }^{2}$ Department of Mechanical Engineering, Halu Oleo University, Kendari, Indonesia \\ Email: b861007b@mails.cc.ehime-u.ac.jp
}

How to cite this paper: Sudarsono and Ogi, K. (2017) Fatigue Behavior of OpenHoled CFRP Laminates with Initially Cut Fibers. Open Journal of Composite Materials, 7, 49-62.

http://dx.doi.org/10.4236/ojcm.2017.71003

Received: December 12, 2016

Accepted: January 19, 2017

Published: January 22, 2017

Copyright (c) 2017 by authors and Scientific Research Publishing Inc. This work is licensed under the Creative Commons Attribution International License (CC BY 4.0).

http://creativecommons.org/licenses/by/4.0/

cc) (i) Open Access

\begin{abstract}
Carbon fiber-reinforced plastic (CFRP) laminates with initially cut fibers (ICFs) have good formability without large degradation of static strength; however, their fatigue behavior has not been investigated thus far. In this paper, we investigated fatigue behavior and damage progress of open-holed CFRP laminates with ICFs having interlayers. Three types of CFRP laminates were employed: a laminate without ICF fabricated using an autoclave (Continuous-A), a laminate with ICF fabricated using an autoclave (ICF-A) and a laminate with ICF fabricated using press molding (ICF-P). First, fatigue test was conducted to obtain $S$ (maximum stress) $N$ (the number of cycles to failure) curves in order to reveal fatigue strength. The fatigue tests for several specimens were interrupted at three prescribed numbers of cycles to observe damage progress. It is found that the Continuous-A laminate shows little strength degradation in the $S-N$ curve while fatigue strength in both ICF laminates is decreased by approximately $30 \%$ at $N$ of $10^{6}$. In contrast, the damage progress of the ICF-P laminate is the least among the three laminates while the delamination progress at both edges and around the hole in the Continuous- $\mathrm{A}$ laminate is the most prominent.
\end{abstract}

\section{Keywords}

Carbon Fiber-Reinforced Plastic, Fatigue, Initially Cut Fibers, Open-Holed, Interlayer

\section{Introduction}

Recently, carbon fiber-reinforced plastics (CFRPs) have been widely applied to primary structural components of aircraft and automobiles because of their contribution to higher fuel efficiency and lower emission of $\mathrm{CO}_{2}$. Such structural components often have circular holes for several technical reasons such as joining, weight reduction and functional needs. In addition, these components are frequently subjected to cyclic loads 
and vibrations, which may cause degradation of structural integrity because of fatigue damage.

In particular, for design requirements and functional needs, an automobile is composed of many complexly shaped components. It is quite difficult to fabricate such components using only conventional CFRP prepreg with continuous fiber owing to its poor formability. In contrast, discontinuous fiber-reinforced plastics fabricated by sheet molding compound (SMC) or injection molding have already been used as automotive parts since they have good molding flowability. However, their strength is much lower than that of composites reinforced with continuous fiber. Therefore, a new material, called unidirectionally arrayed chopped strands, was developed by Taketa et al. [1] by introducing initially cut fibers (ICFs) into CFRP prepreg. The strength and uniformity of layer structure of the ICF laminate were found to be superior to SMCs.

Several experimental results have been reported on ICF laminates thus far. In the subsequent paper by Taketa et al. [2], the effects of interlaminar toughening on suppression of delamination in ICF laminates were experimentally studied. Yashiro \& Ogi [3] investigated the effects of ICFs on fracture behavior in CFRP cross-ply laminates, having alternate or identical ICF angle $\pm \theta$ in the $0^{\circ}$ plies. Next, Taketa et al. [4] proposed a technique for enhancing strength and uniformity of layer structure in ICF laminates by introducing ICFs with small angles for the fiber direction. Furthermore, Taketa et al. [5] also investigated mechanical properties of ICF laminates for the application as structural material for complex geometry. They found that the ICF laminates maintain high mechanical properties after forming to complex shapes. Li et al. [6] proposed two newly designed ICF prepregs with discontinuous staggered angled ICFs and discontinuous bi-angled ICFs. Li et al. [7] also studied the damage progression in three kinds of ICF quasi-isotropic (QI) laminates under tension by finite element simulation based on a multiscale analysis.

Meanwhile, numerous studies have been performed on fatigue behavior of various kinds of open-holed CFRP composites under a variety of loading conditions. O'Higgins et al. [8] studied the open hole tension (OHT) characteristics of CFRP and glass fiber reinforced plastic (GFRP). Mall et al. [9] investigated the tension-compression fatigue behavior of unnotched and notched carbon/epoxy composites manufactured using the H-VaRTM (heated vacuum-assisted resin transfer molding). Yashiro and Okabe [10] studied fatigue damage identification in open-holed CFRP laminates by using embedded fiber Bragg grating (FBG) sensors. Kawai and Shiratsuchi [11] investigated the effect of notch on fatigue behavior of CFRP laminates with different stacking configurations. More recently, Fujita et al. [12] investigated mechanical properties such as compression after impact and compressive strength with OHT specimens of ICF laminates with toughened interlayers. Most of the above studies on open-holed laminates have been performed on continuous CFRP laminates while very little attention has been paid to fatigue behavior of open-holed ICF CFRP laminates.

The objective of the present study is to investigate fatigue behavior and damage progress of open-holed ICF CFRP laminates with toughened interlayers. Two kinds ofQI ICF laminates were fabricated by autoclave and hot press molding methods. For comparison, a QI laminate made of continuous prepreg is also manufactured by the 
autoclave method. First, $S$ (maximum stress)- $N$ (the number of cycles to failure) curves were measured for the above three laminates. Second, the internal fatigue damage progress was observed using optical microscopy and radiography. Finally, the effect of interlayers on fatigue progress was discussed based on the microscopic observation of the damages.

\section{Experimental Procedure}

The prepreg used in this study is made of carbon fiber (volume fraction 0.58) and epoxy resin with interlayers, (T800S/\#3900-2B, Toray Industries). This prepreg system contains about $30 \mu \mathrm{m}$ thick interlayers including tough thermoplastic particles on the $150 \mu \mathrm{m}$ thick base CFRP layer. A micrograph on the cross-section of the laminate is presented in Figure 1.

In this study, we made ICF sheets as proposed by Taketa et al. [1]. An automatic cuttingmachine with a special tangential blade was employed to mechanically introduce ICFs into the prepreg. The schematic of the ICF patterns in this study is illustrated in Figure 2. $1 \mathrm{~mm}$-long staggered ICFs were arrayed at an interval of $25 \mathrm{~mm}$ in the fiber direction. Two types of ICF laminates with an ICF angle $\theta$ of $22.5^{\circ}$ were fabricated by using the autoclave method (ICF-A) and press molding method (ICF-P). The ICF plies were prepared by cutting $300 \mathrm{~mm}$ and $250 \mathrm{~mm}$ square prepreg sheets for the ICF-A and

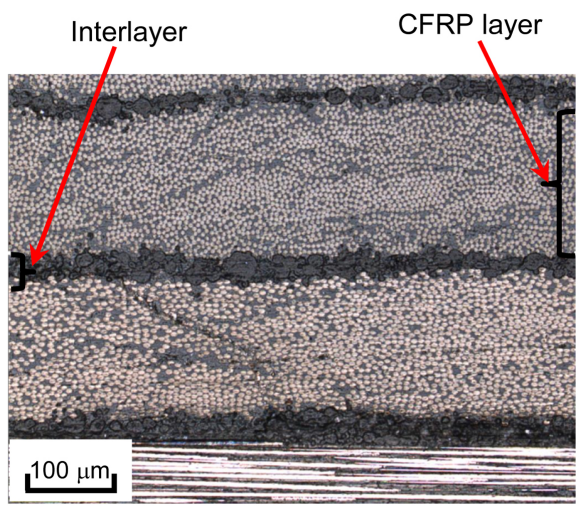

(a)

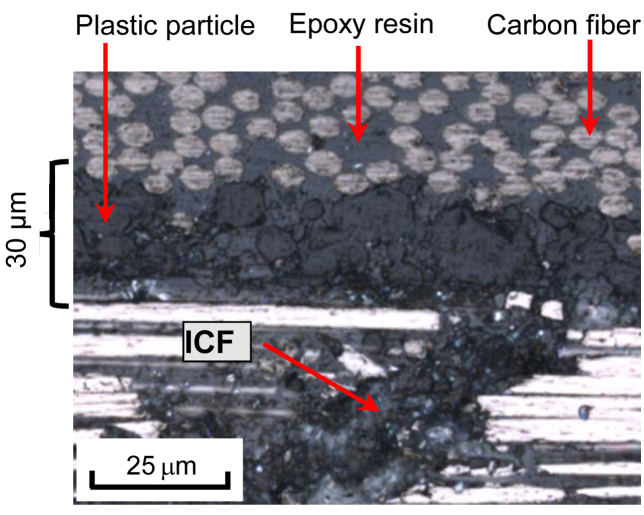

(b)

Figure 1. Microstructure of the CFRP laminate used in the fatigue test.

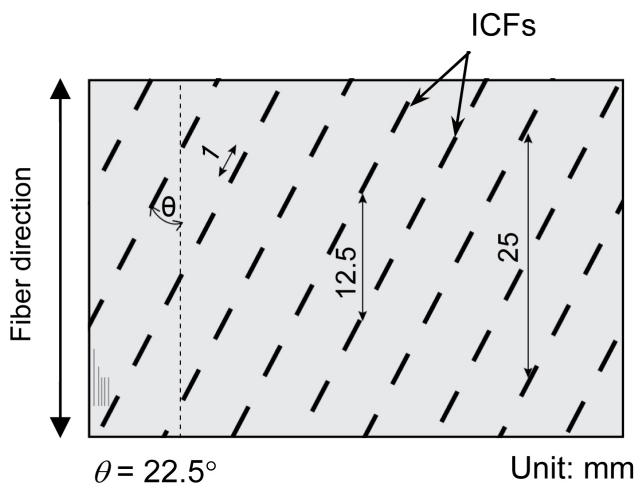

Figure 2. Schematic of ICF patterns introduced in the prepreg. 
ICF-P laminates, respectively.

An ICF-A QI laminate was built by stacking ICF plies in a sequence of [45/0/-45/90] s and then cured in the autoclave. The schematic of the press molding process is illustrated in Figure 3. An ICF-P QI laminate was made by stacking ICF plies in a sequence of $[45 / 0 /-45 / 90]_{2 s}$ into a mold (300 $\mathrm{mm}$ square) and cured at a pressure of 0.3 $\mathrm{MPa}$ and a temperature of $150^{\circ} \mathrm{C}$ for $30 \mathrm{~min}$, during which its area increases from $70 \%$ to $100 \%$ of themold. For comparison, a Continuous-A QI laminate was also fabricated by stacking the conventional prepreg ( $250 \mathrm{~mm}$ square) without ICFs in a sequence of $[45 / 0 /-45 / 90]_{s}$ and then cured using autoclave method.

OHT specimens were then cut out from laminates according to the ASTM standard (D5766). The dimensions and geometry of OHT specimens are shown in Figure 4. The specimen is $304 \mathrm{~mm}$ long and $38 \mathrm{~mm}$ wide. A $6.3 \mathrm{~mm}$ diameter hole was made at the center of the specimen by using a drilling machine. No end tabs were bonded on the specimen because fracture did not occur near the grip area. Table 1 summarizes the stacking sequence, the thickness and static tensile strength of the Continuous-A, ICF-A and ICF-P OHT specimens.

The tensile fatigue tests were conducted at a room temperature with a sinusoidal waveform under a load-control condition using a hydraulic testing machine (8516 INSTRON). All the tests were performed at a stress ratio of 0.1 and at a frequency of 3 Hz. The maximum stress $\sigma_{\max }$ was varied between $60 \%$ and $95 \%$ of the static tensile

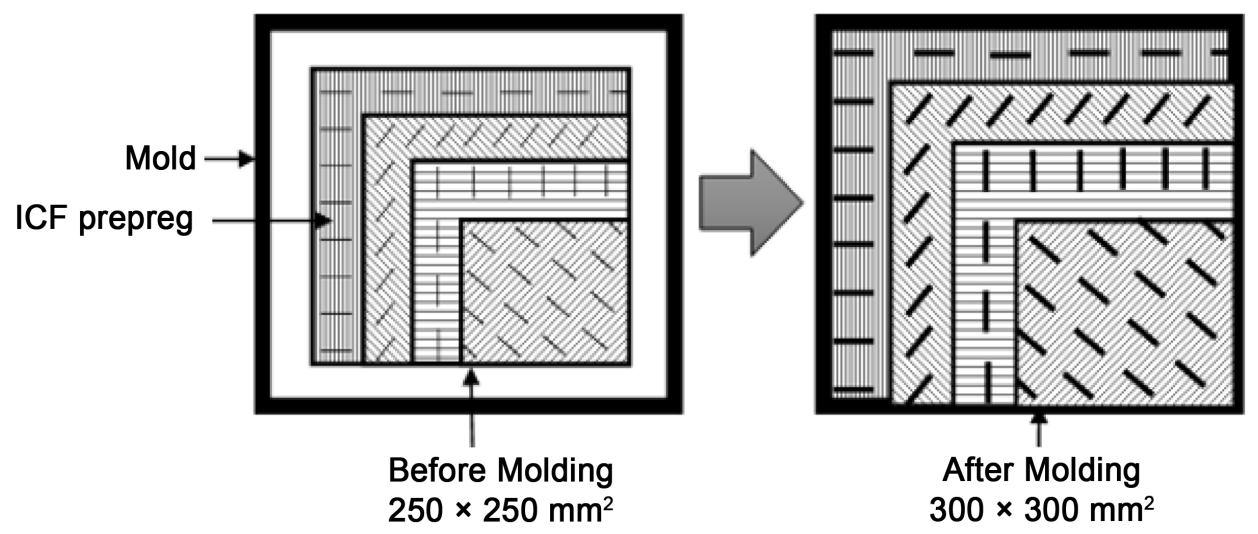

Figure 3. Schematic of an ICF-P laminate before and after press-molding.

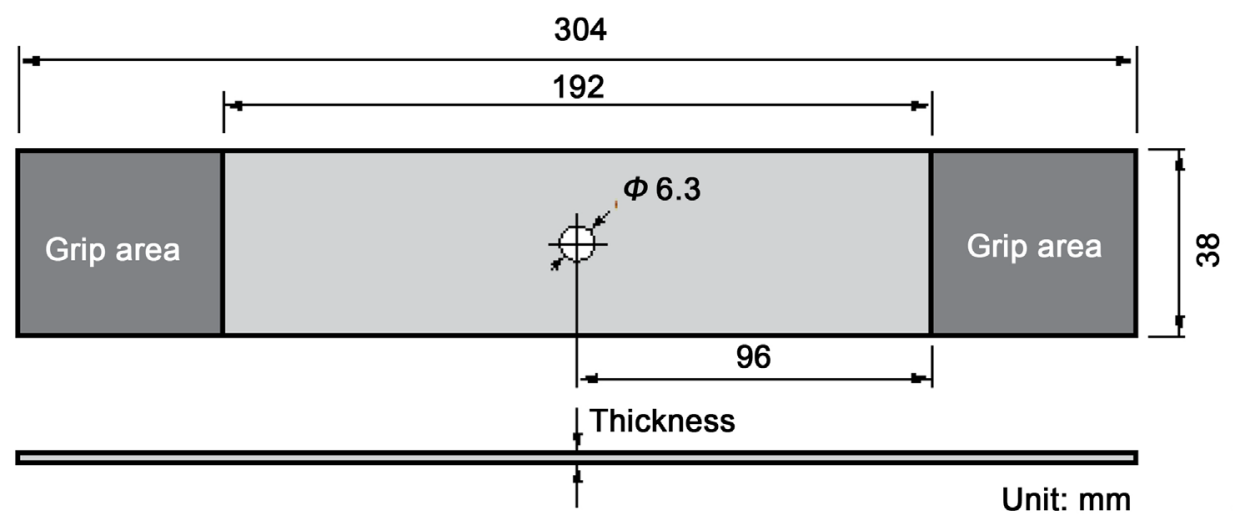

Figure 4. Dimensions of the open hole tension (OHT) specimen. 
Table 1. Stacking sequence, thickness and static tensile strength of OHT specimens.

\begin{tabular}{|c|c|c|c|c|}
\hline \multirow{2}{*}{ Laminate } & \multirow{2}{*}{$\begin{array}{l}\text { Stacking } \\
\text { sequence }\end{array}$} & \multicolumn{2}{|c|}{ Thickness } & \multirow{2}{*}{$\begin{array}{l}\text { Static tensile strength } \\
\qquad(\mathrm{MPa})\end{array}$} \\
\hline & & Laminate $(\mathrm{mm})$ & Ply (mm) & \\
\hline Continuous-A & {$[+45 / 0 /-45 / 90]_{s}$} & 1.55 & 0.194 & 531.2 \\
\hline ICF-A & {$[+45 / 0 /-45 / 90]_{\mathrm{s}}$} & 1.56 & 0.195 & 432.7 \\
\hline ICF-P & {$[+45 / 0 /-45 / 90]_{2 \mathrm{~s}}$} & 2.16 & 0.135 & 531.6 \\
\hline
\end{tabular}

strength $\sigma_{\text {Онт }}$ of each ICF OHT specimen. The tests were terminated at $N$ of $10^{6}$ cycles even if no failure occurred. In order to quantitatively evaluate the magnitude of damage, fatigue tests $\left(\sigma_{\max }=0.73 \sigma_{\mathrm{OHT}}\right)$ of one specimen for each laminate was interrupted at the prescribed numbers of cycles $\left(N=10^{3}, 10^{4}, 10^{5}\right)$ before final failure. The internal damage progress during the fatigue test was observed using transmissive radiography (SOFTEX M-100) with the aid of zinc iodide as a contrast medium. The projected internal damage area was then quantitatively measured using commercial imaging software.

\section{Results and Discussion}

\section{1. $S$ - $N$ Curves}

Figure 5 shows the $S$ - $N$ curves for the Continuous-A, ICF-A and ICF-P laminates. The $S-N$ curve of the Continuous-A laminate shows the least reduction of fatigue strength among the three laminates (approximately by $5 \%$ of the static tensile strength at $10^{6}$ cycles). In contrast, the $S$ - $N$ curve behavior of the ICF-A and ICF-P laminates was similar although the static strength of the ICF-P laminate was higher than that of the ICF-A laminate. The fatigue strength in both laminates decreased approximately by $30 \%$ of their static tensile strength at $N$ of $10^{6}$ cycles. Comparing the results of Continuous-A and ICF-A laminates, both the static tensile strength and fatigue strength of the ICF-A laminate are smaller than those of the Continuous-A laminate. This indicates that damage are easily initiated from ICFs at relatively low stress levels or low numbers of cycles, as shown later. Moreover, comparing the ICF-A and ICF-P laminates, both the static tensile strength and fatigue strength of the ICF-P laminate (ply thickness 1.56 $\mathrm{mm}$ ) were higher than those of the ICF-A laminate (ply thickness $2.16 \mathrm{~mm}$ ). The main reason for higher strength of the ICF-P laminate is the thinner plies as has been analytically explained by Taketa et al. [1].

\subsection{Damage Progress}

Figure 6(a), Figure 6(c), Figure 7(a), Figure 7(c), Figure 8(a) and Figure 8(c) depict the schematics of damage progress viewed from the top and projected soft X-ray photosfor the Continuous-A, ICF-A and ICF-P laminates, respectively. Figure 6(a), Figure 7(a) and Figure 8(a) are illustrations based on the X-ray photos while Figure 6(b), Figure $7(\mathrm{~b})$ and Figure $8(\mathrm{~b})$ are ones based on the optical micrographs on the edge surfaces. Figure 9 and Figure 10 present the crack density and delamination area around the hole, respectively, for the three laminates at three numbers of cycles. The measurement area around the hole for crack density and delamination is $293 \mathrm{~mm}^{2}$. 


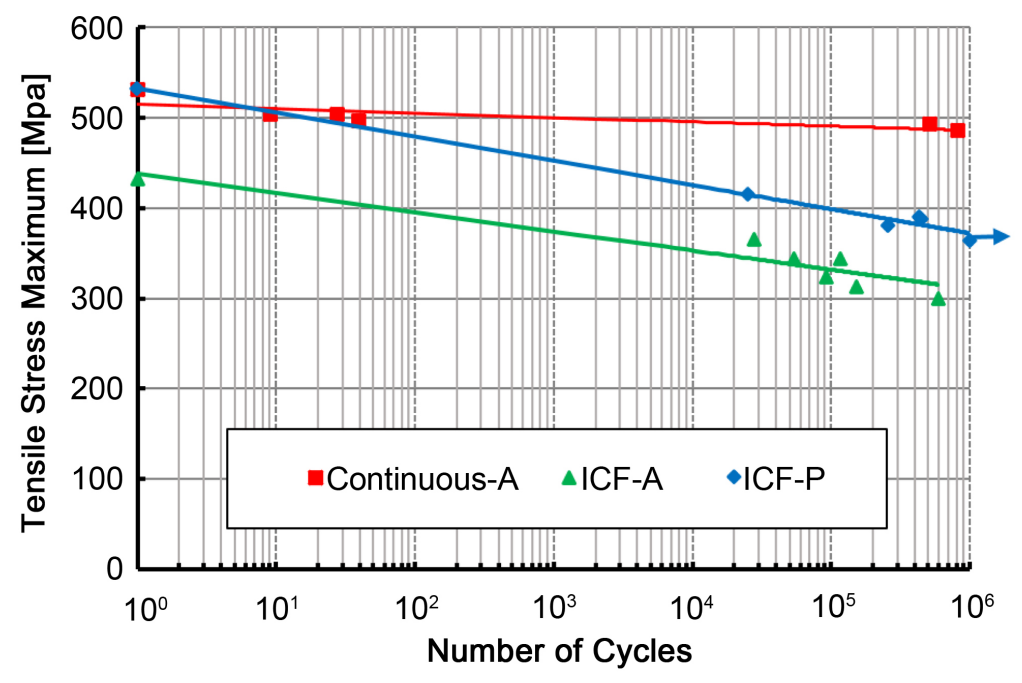

Figure 5. $S$ - $N$ curves of three types of OHT specimens.

First, at $N$ of $10^{3}$, transverse cracks in the $\pm 45^{\circ}$ and $90^{\circ}$ plies and splitting cracks in the $0^{\circ}$ plies are initiated from the hole roots (arrows A) as well as from the both edges in all the laminates. The crack density, which is defined as the sum of the crack length per unit area around the hole, in the Continuous-A laminate is the largest among the three laminates as shown in the Figure 9. This is mainly due to a lot of cracks propagating from the splitting cracks in the longitudinal ply. Comparing both ICF laminates, the crack density in the ICF-P laminate is smaller than that in the ICF-A laminate since the ply is thinner in the ICF-P laminate. On the other hand, the delamination area is comparable in the three laminates.

Second, at $N$ of $10^{4}$, the transverse cracks from the both free edges propagated and were connected with each other across the width of the specimens. In the ICF-A laminate (Figure 7), a lot of cracks were newly generated from ICFs existing not only around the hole but also away from the hole. Consequently, the crack density in the ICF-A laminate is the largest among the three laminates. In contrast, the crack density and delamination area are the smallest in the ICF-P laminate.

Third, at $N$ of $10^{5}$, the density and length of cracks increase rapidly, especially in the Continuous-A and ICF-A laminates (Figure 9). The delamination propagating around the hole in the Continuous-A and ICF-A laminates are more remarkable than that in the ICF-P laminateas shown in Figure 10. As a result, the ICF-P laminate shows the smallest damage growth among the three laminates. This is because the initiation and propagation of matrix cracking are suppressed as the ply becomes thinner. In addition, the area of the cracking and delamination is limited near the hole roots as shown in Figure 8(c).

Figure 6(b), Figure 7(b) and Figure 8(b) schematically show the damage progress on the free edge surfaces of the three laminates. In the Continuous-A laminate (Figure 6), the damage scenario is as follows: 1) Transverse cracks are initiated in the $90^{\circ}$ and \pm $45^{\circ}$ plies. 2) The number of transverse cracks increases with increasing N. 3) Adjacent transverse cracks are connected with each other by way of the ply interfaces. 4) Delamination is generated and extends along the specimen length and across the specimen 

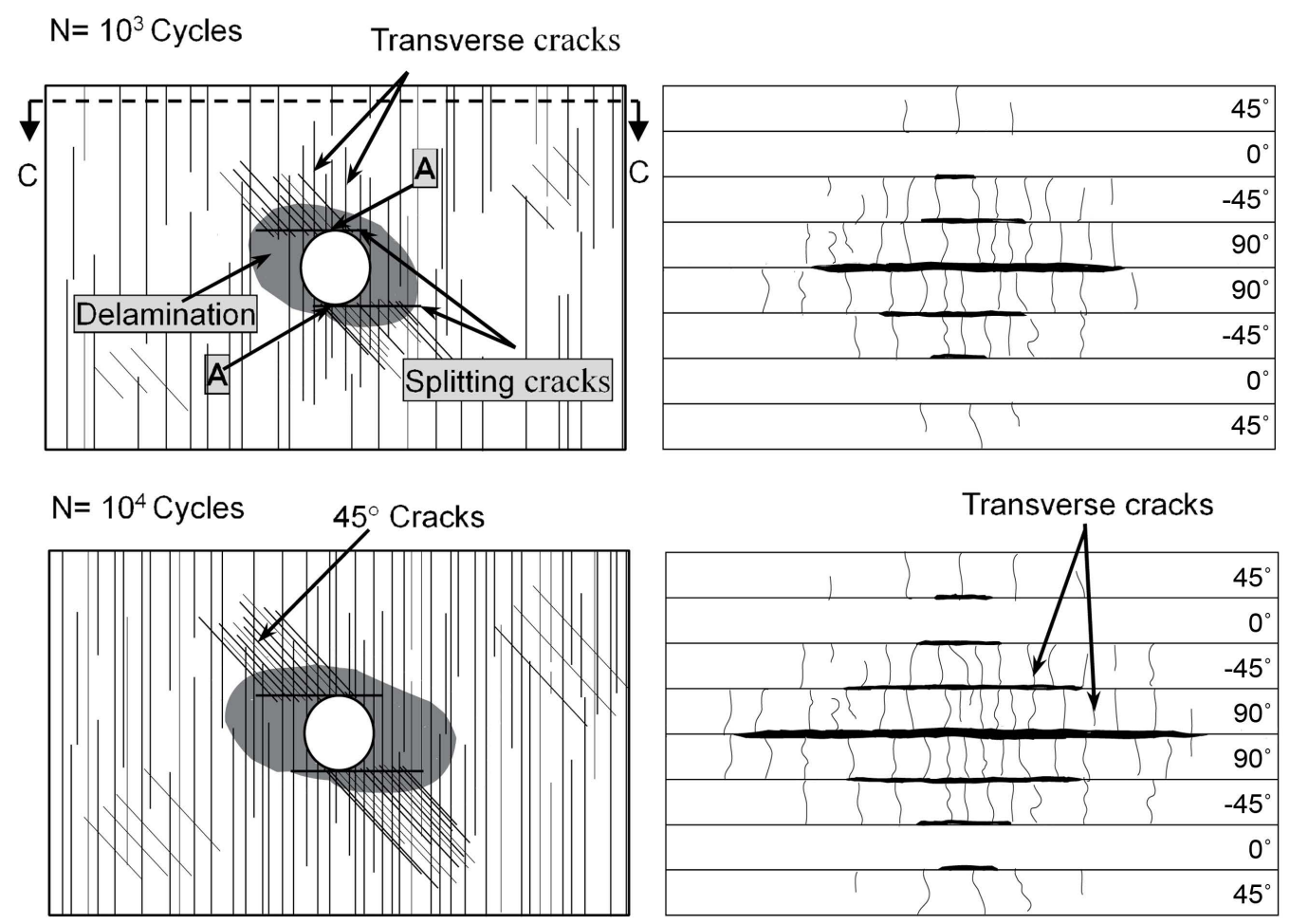

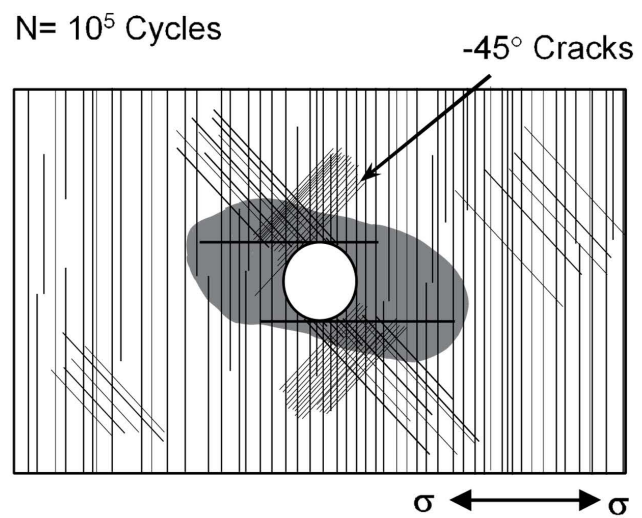

(a) Top views

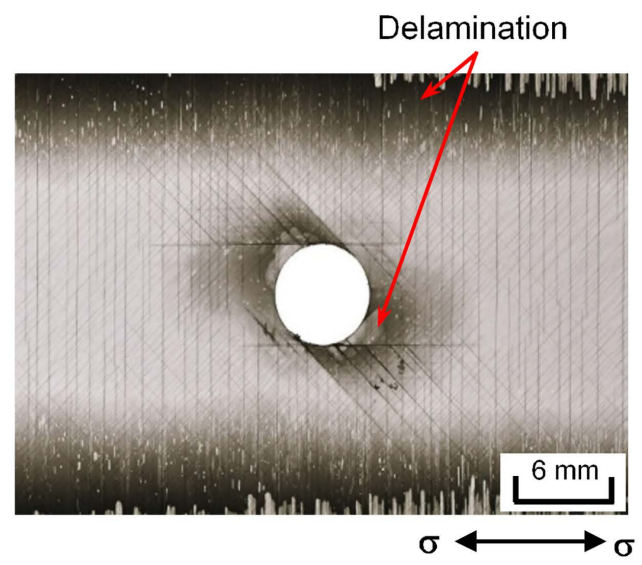

(c) Soft X-ray photo around the hole

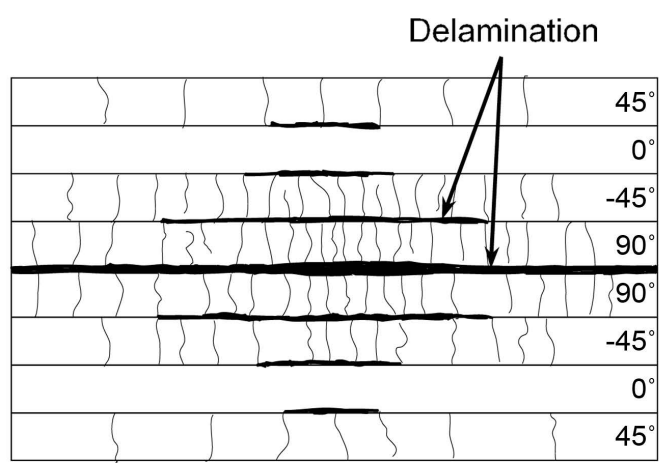

(b) Edge views (C-C)

Cracks

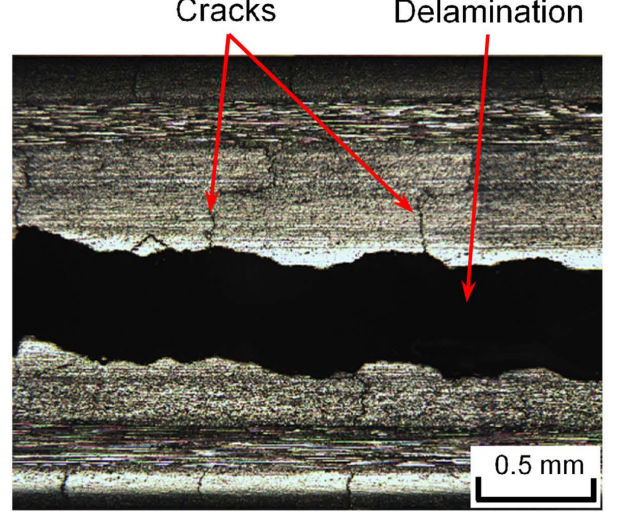

(d) Optical micrograph on the edge

Figure 6. (a) Top and (b) edge views of schematic damage progress, (c) an X-ray photo and (d) and an optical micrograph on the edge in the Continuous-A specimen. 

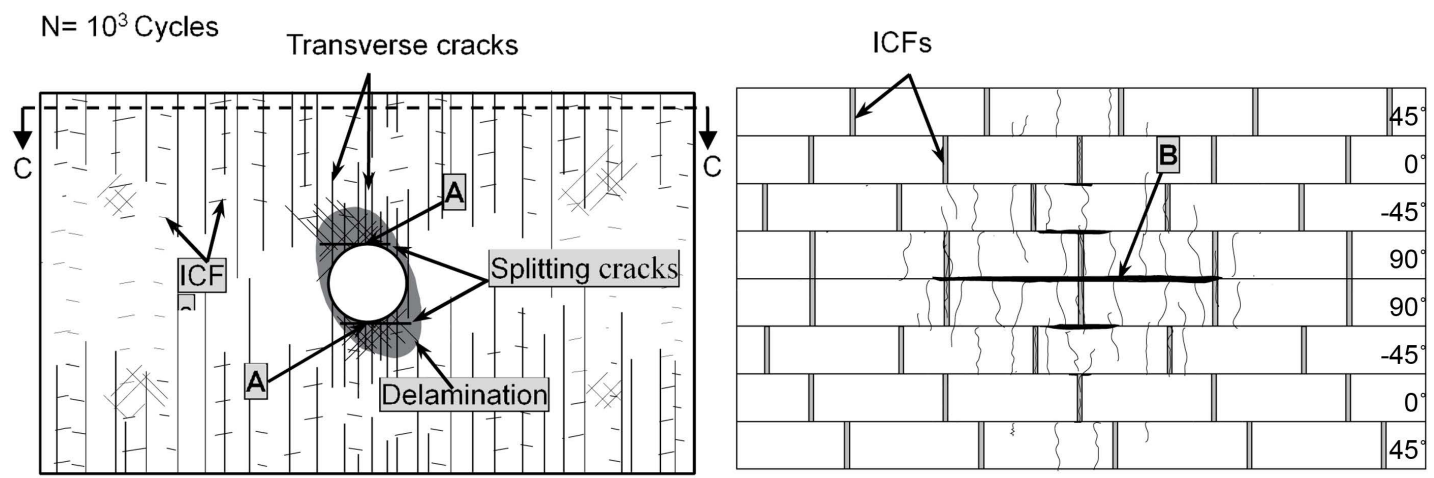

$\mathrm{N}=10^{4}$ Cycles
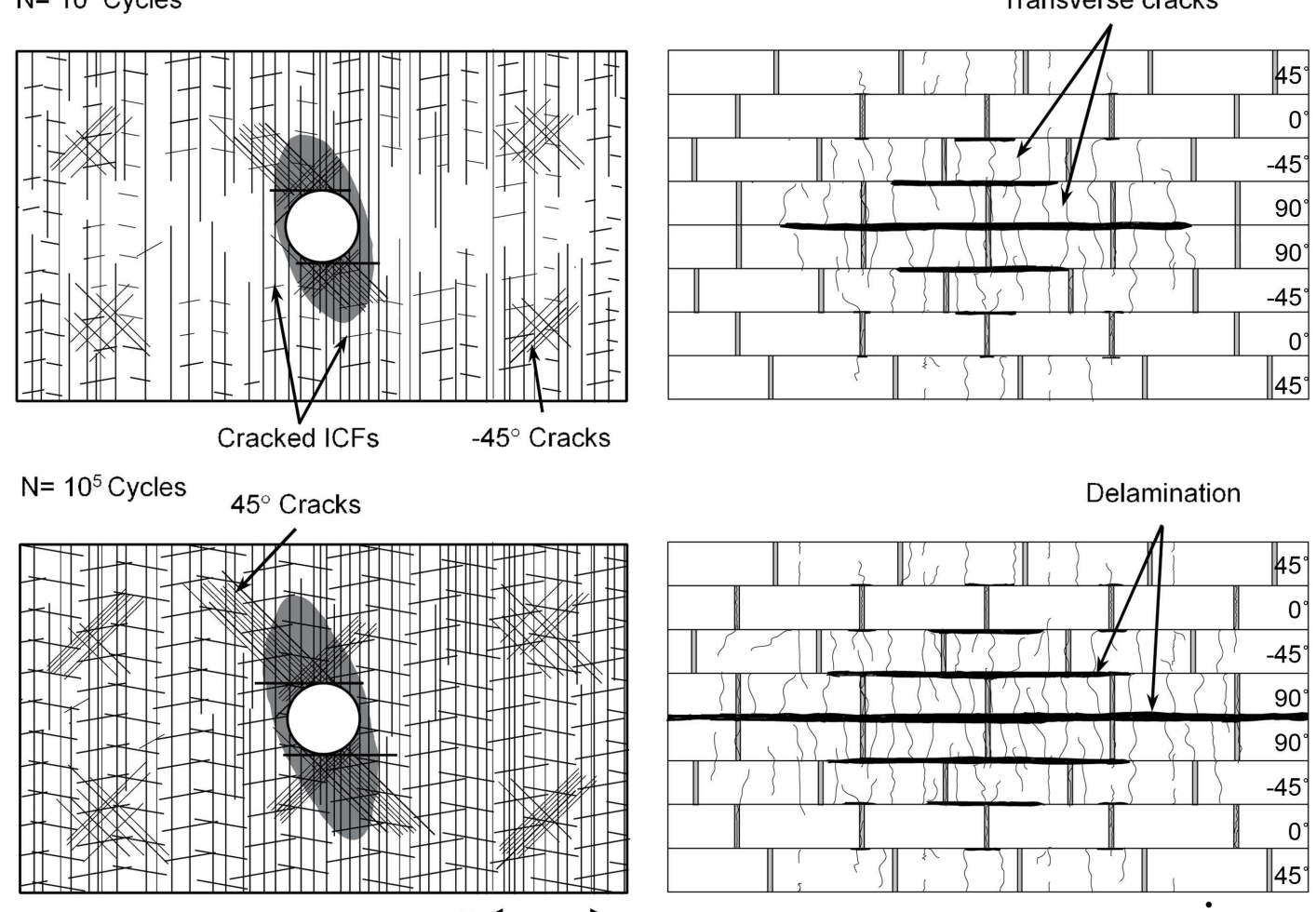

(a) Top views

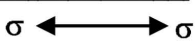

Delamination Cracked ICFs

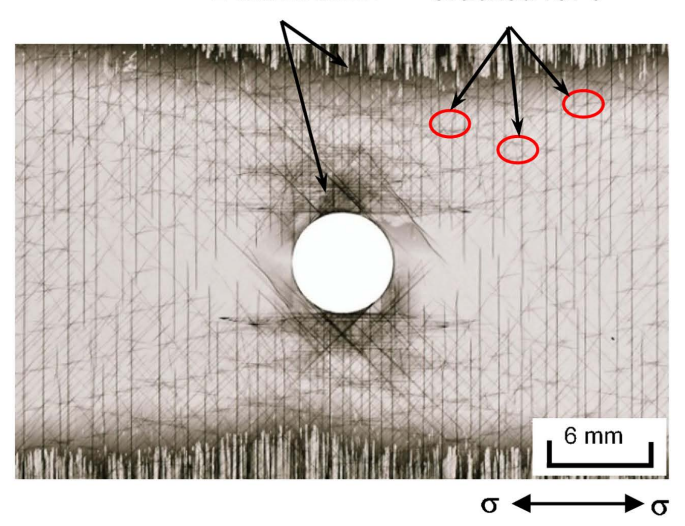

(c) Soft X-ray photo around the hole

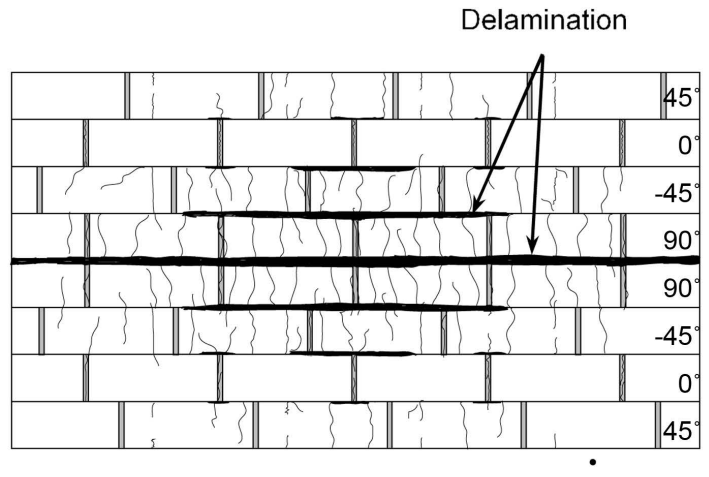

(b) Edge views (C-C)

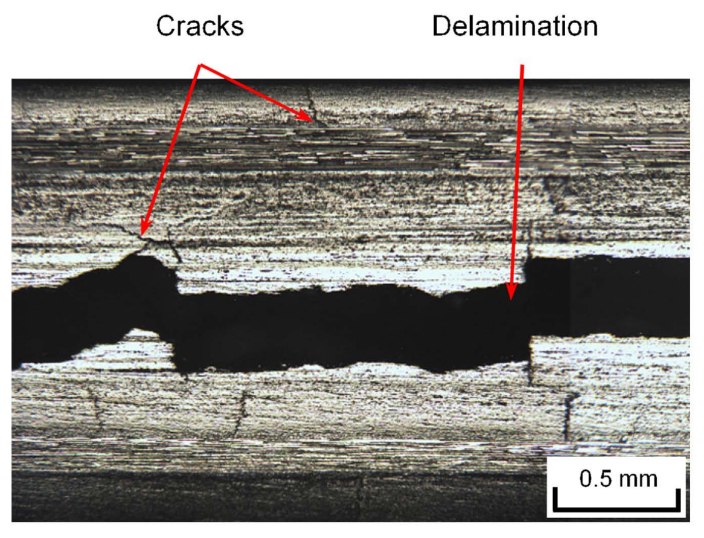

(d) Optical micrograph on the edge

Figure 7. (a) Top and (b) edge views of schematic damage progress, (c) an X-ray photo and (d) and an optical micrograph on the edge in the ICF-A specimen. 


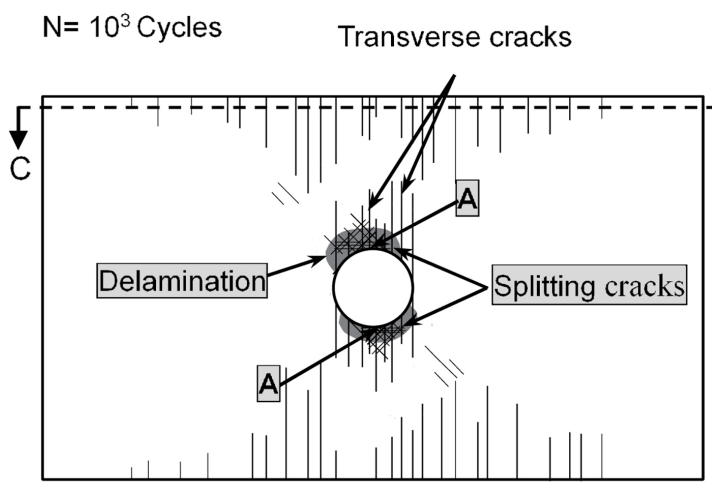

$\mathrm{N}=10^{4}$ Cycles
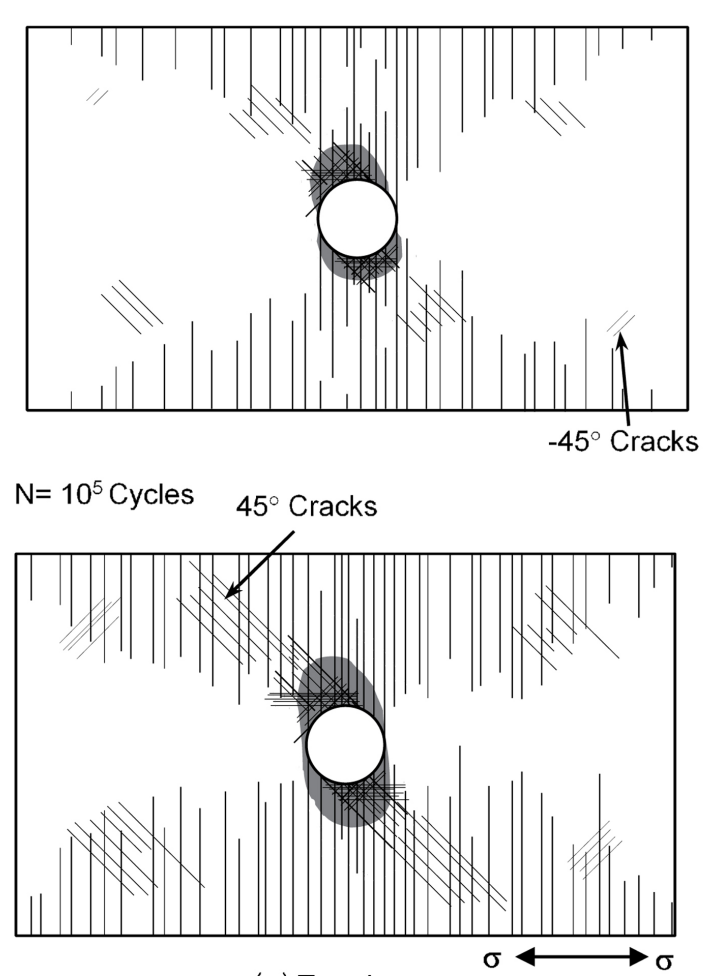

(a) Top views

Delamination

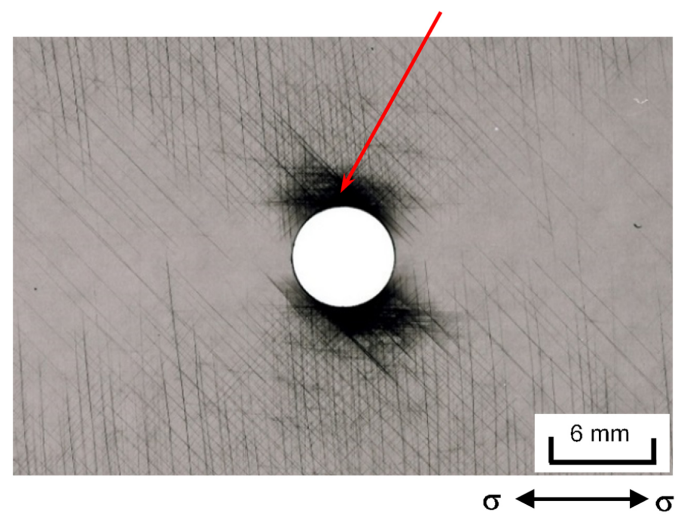

(c) X-ray photo around the hole

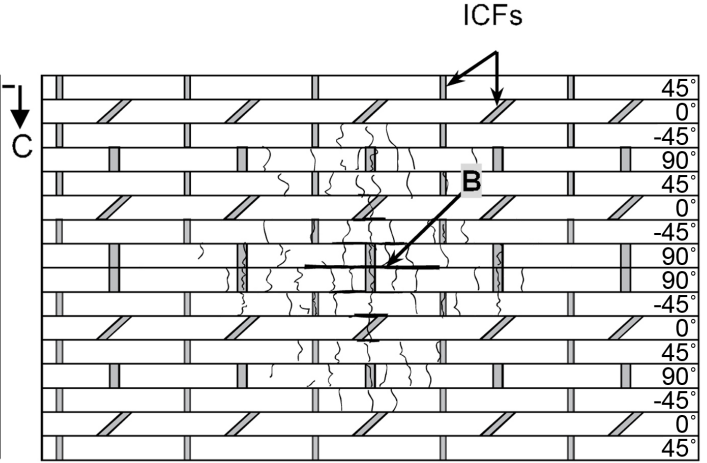

Transverse cracks

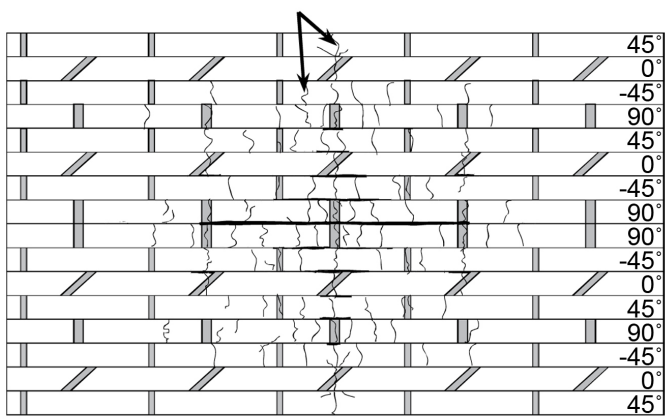

Delamination

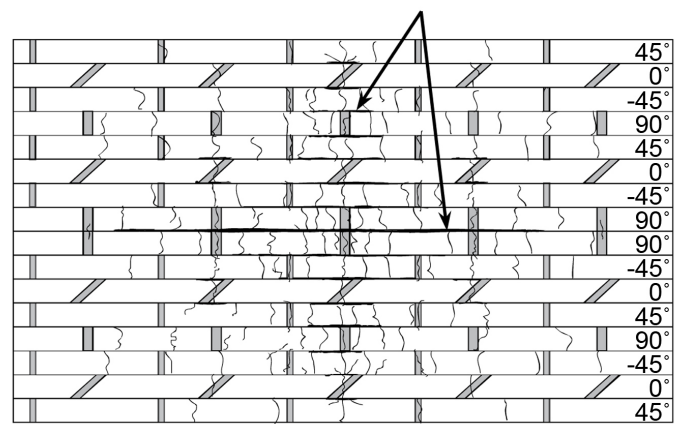

(b) Edge views (C-C)

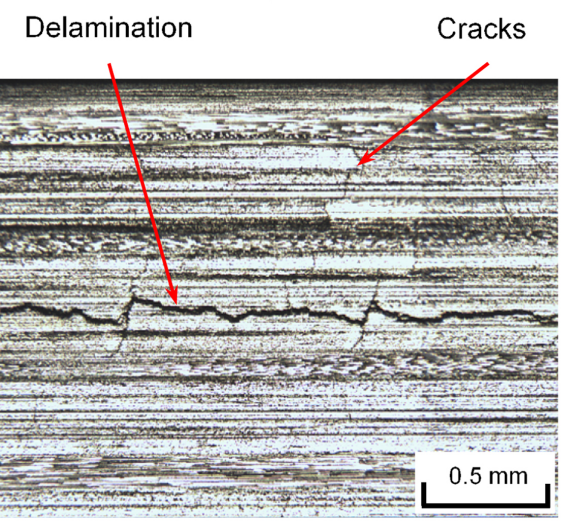

(d) Optical micrograph on the edge

Figure 8. (a) Top and (b) edge views of schematic damage progress, (c) an X-ray photo and (d) and an optical micrograph on the edge in the ICF-P specimen. 


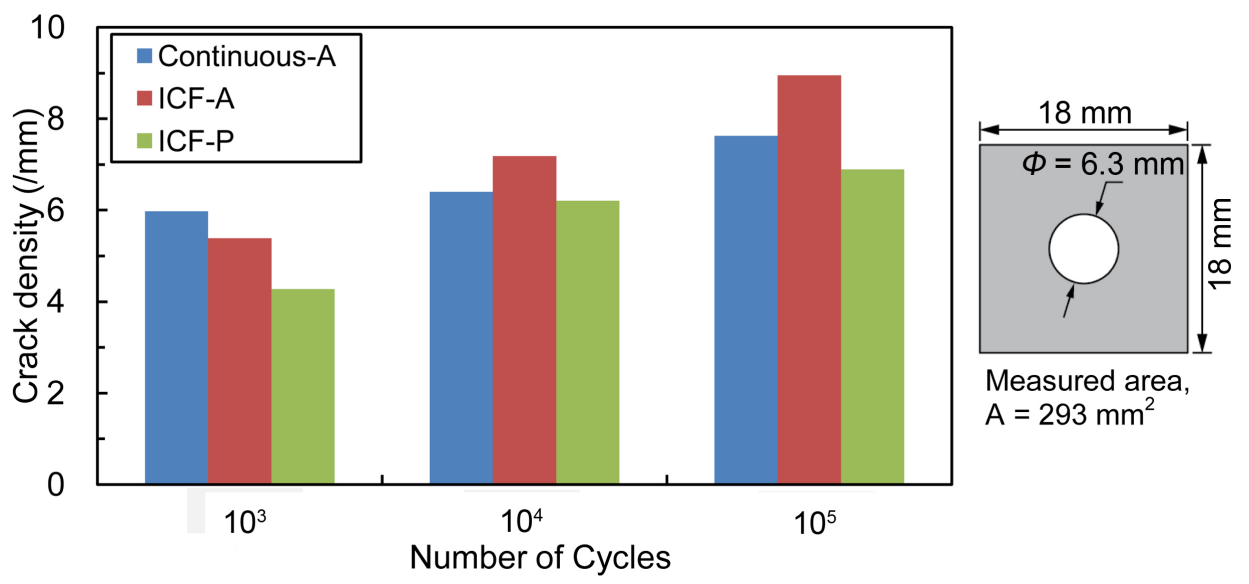

Figure 9. Crack density around the hole at three numbers of cycles for the three laminates.

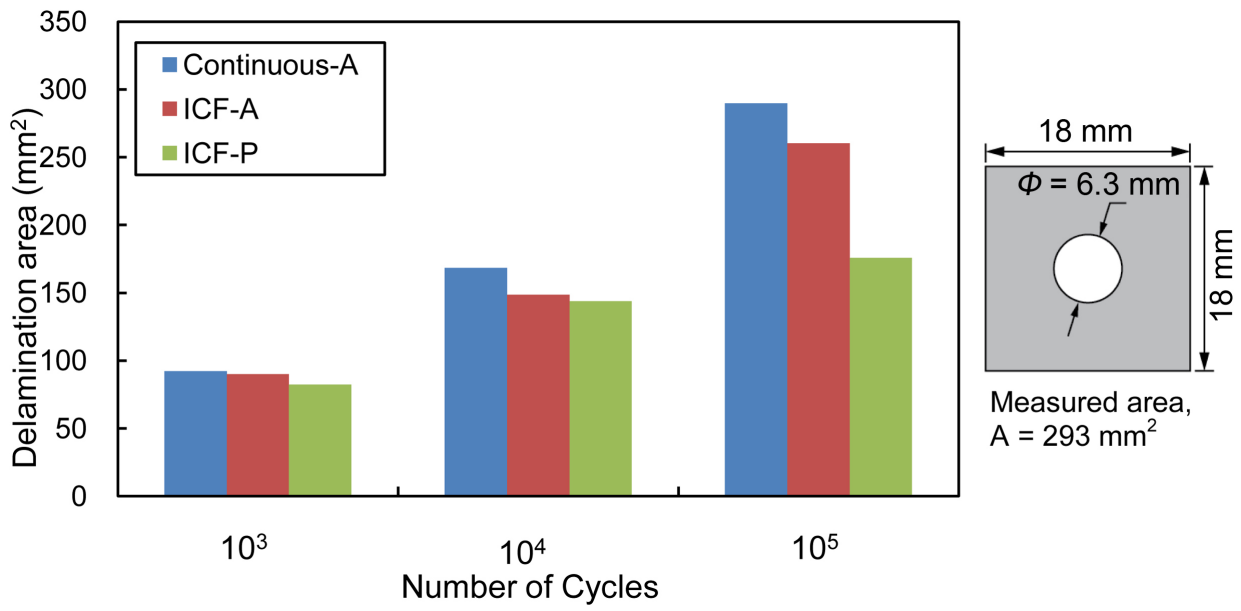

Figure 10. Delamination area around the hole at three numbers of cycles for the three laminates.

width. The delaminations are mainly caused by the interlaminar shear stress at the both free edges (Figure 6(d), Figure 7(d) and Figure 8(d)) and the hole roots (Figure 6(a), Figure 7(a) and Figure 8(a)). On the other hand, the damage progress in the ICF-A (Figure 7) and ICF-P laminates (Figure 8) are summarized as follows: 1) Transverse cracks independent of ICFs occur in the $90^{\circ}$ and $\pm 45^{\circ}$ plies. 2) New cracks extend from the tips of ICFs only in the ICF-A laminate. 3) Adjacent transverse cracks are connected with each other through the ply interfaces. 4) Delamination is generated and extends at the ply interfaces. In particular, the delamination occurs at the ply interfaces near ICFs at the early stage of cycles (arrows B).

From the above schematics, it is found that the delamination in the Continuous- $\mathrm{A}$ laminate is more prominent than that in the ICF-A laminate. Contrarily, relatively small delamination locally extends around the hole in the ICF-P laminate (Figure $8(d))$. It is revealed that matrix cracks are relatively difficult to propagate in the ICF-P laminate with thinner plies.

The final fracture behavior for the three types of laminates are schematically shown in Figure 11. All the specimens exhibit a brittle fracture manner. In the Continuous-A laminate, the delamination at the interface between the $45^{\circ}$ and $0^{\circ}$ plies dominates the 


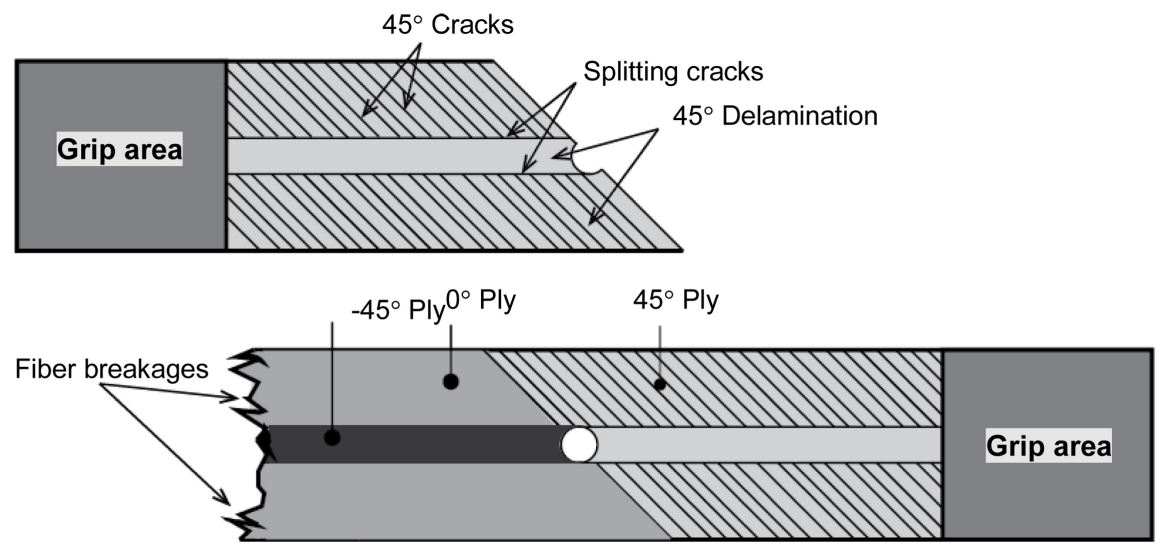

(a) Continuous-A laminate

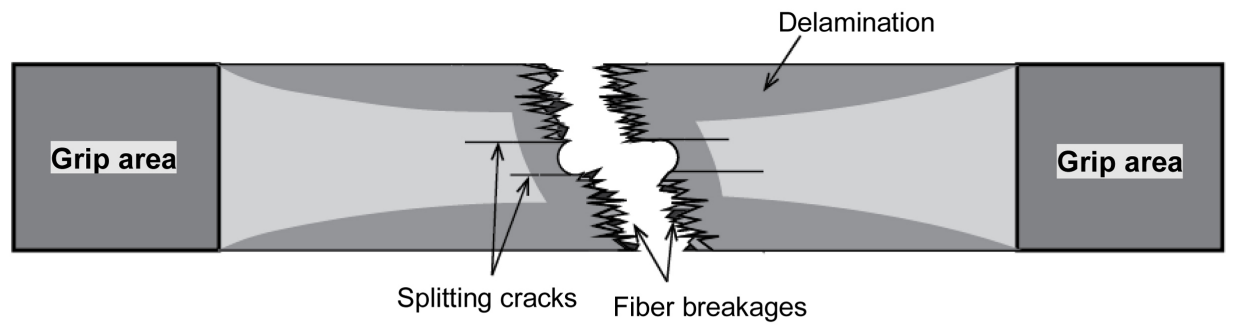

(b) ICF-A laminate

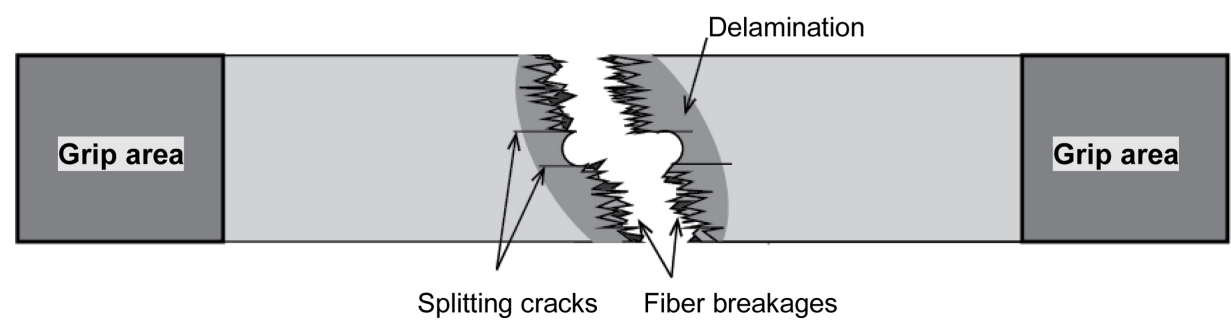

(c) ICF-P laminate

Figure 11. Schematics of final fracture behavior of the three OHT specimens.

final failure. The splitting cracks generated from the hole roots in the $0^{\circ}$ plies propagate along the specimen length to induce the delamination, which causes full peel-off of the plies at the $0 \%-45^{\circ}$ interfaces. The delamination starting from the hole propagates in the loading (longitudinal) direction and reaches both ends of the specimen at the final failure stage. In contrast, in the both ICF laminates, the final fracture mode is fiber breakage around the hole, although free-edge delamination is more remarkable in the ICF-A laminate. In addition, the damages including delamination and fiber breakage in the both ICF laminates tend to extend in the transverse direction rather than in the longitudinal direction. The propagation behavior of the splitting cracks in the $0^{\circ}$ plies in the Continuous-A, ICF-A, and ICF-P laminates is illustrated in Figure 12. The ICFs hinder propagation of the splitting cracks in the ICF laminates and induce the crack deflection (Figure 12(b) and Figure 12(c)). Consequently, the splitting cracks initiated around the hole in the ICF laminates (Figure 7(a) and Figure 8(a))are shorter than those in the Continuous-A laminate (Figure 6(a)). In addition, multiple splitting cracks are only generated in the ICF-P laminate (Figure 12(c)). Figure 12 also explains the decrease of the fatigue strength in the $S$ - $N$ curves for the ICF-A and ICF-P laminates, 


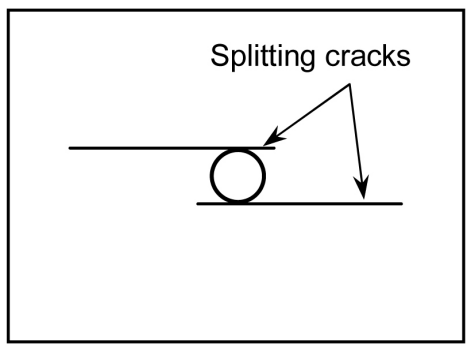

(a). Continuous-A

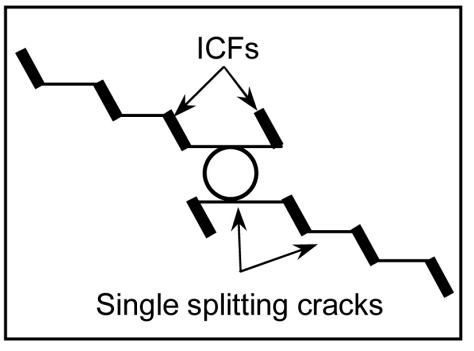

(b). ICF-A

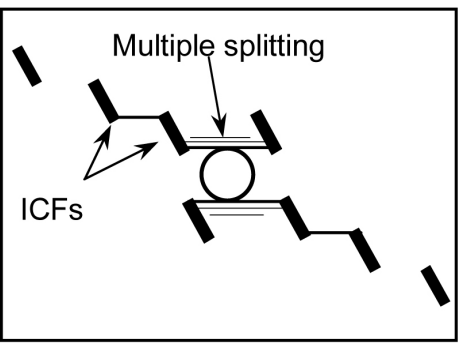

(c). ICF-P

Figure 12. Schematics of split progress in $0^{\circ}$ ply: (a) Continuous-A, (b) ICF-A, and (c) (ICF-P) laminates.

where the intact ligament width becomes smaller by the connection of ICFs. In addition, comparing the present result with the result of static tensile test for the similar OHT specimens [12], it is found that the delamination is more predominant in the fatigue failure. This is presumably because the fatigue delamination propagation occurs during cyclic loading.

\subsection{The Effect of Interlayers}

Figure 13 depicts the scanning electron micrographs of cross-sections near the hole of the specimen after the fatigue test. Two types of cracks are observed; one is generated at the interface between the base ply and the interlayer (Crack B, Figure 13(b)) and the other is initiated in the matrix of the base ply (Crack C, Figure 13(c)). Cracks B and C extend in the directions parallel and perpendicular to the interlayer, respectively. Both cracks are arrested by the interlayer as depicted in Figure 13(b) and Figure 13(c). This result testifies that the interlayer plays a role of a crack arrestor also for fatigue crack propagation even near the hole. Namely, propagation of the cracks generated in the base plies stop near the interfaces between the base plies and the interlayers, resulting in suppression of delamination.

\section{Conclusions}

The fatigue behavior and damage progress in open-holed CFRP laminates with ICF toughened with interlayers are presented. From the experimental results, the following conclusions are derived:

1) The fatigue strength of the Continuous-A laminate is the highest among the three laminates. The decrease ratio of fatigue strength at $N$ of $10^{6}$ is only $5 \%$ of its static strength.

2) The fatigue strength of the ICF-P laminate is higher than that of the ICF-A laminate. However, the decrease ratio of fatigue strength at $N$ of $10^{6}$ is about $30 \%$ of its static strength, which is almost the same in the both ICF laminates.

3) The degree of damage in the ICF-P laminate is the smallest among the three laminates while the increase rate of the crack density is the greatest in the ICF-A laminate with thicker plies.

4) The damage propagation direction around the hole in the Continuous-A laminate is rather longitudinal while that in the both ICF laminates is transverse.

5) The interlayer acts as a crack arrestor for fatigue crack propagation even near the 


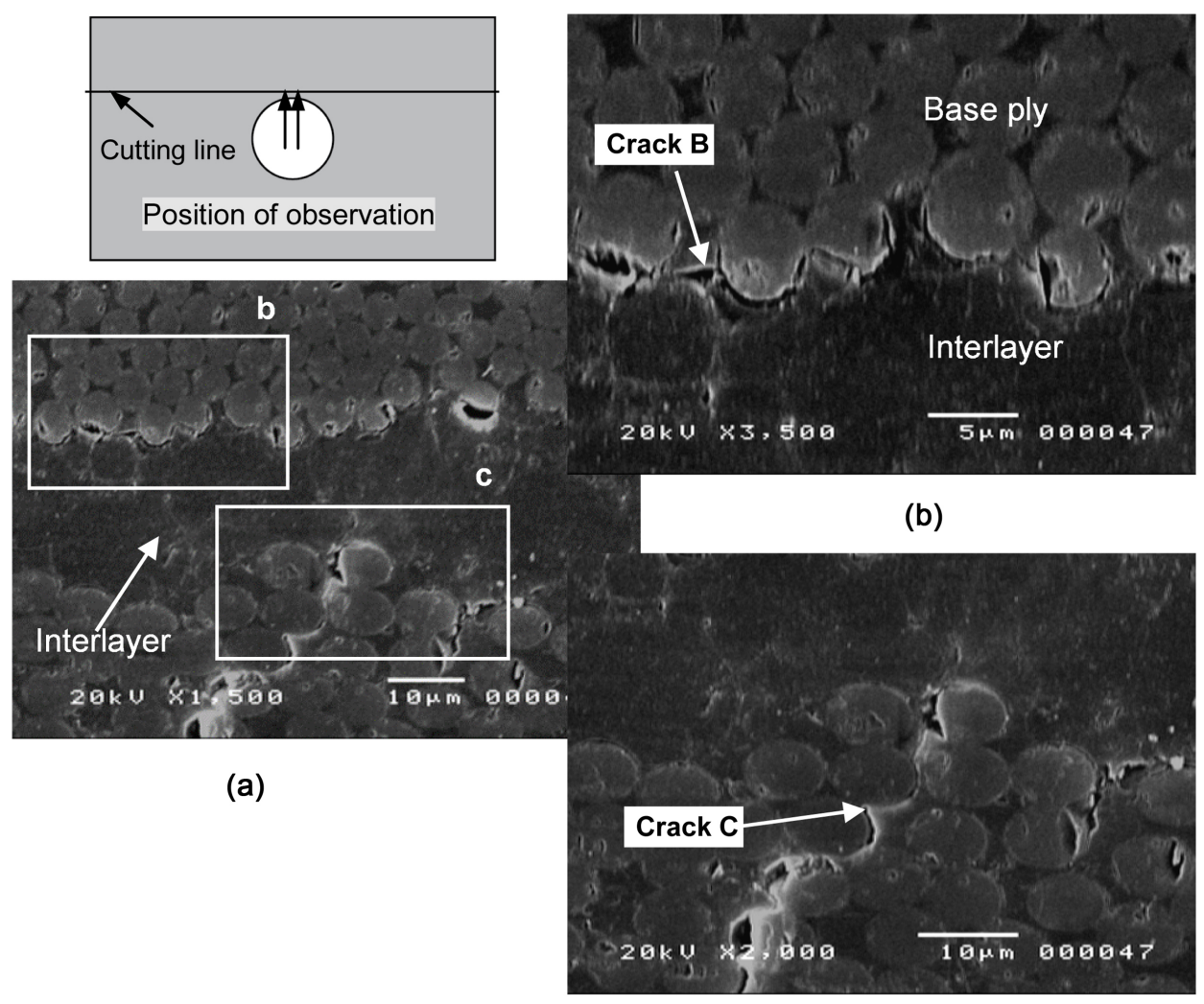

(c)

Figure 13. SEM photos of cross-sections near the hole of the specimen after fatigue test; (a) cracks around interlayer (b) crack at interface, and (c) transverse crack.

hole.

6) Further work is still required to quantitatively predict fatigue damage development in both ICF laminates by finite element analysis.

\section{References}

[1] Taketa, I., Okabe, T. and Kitano, A. (2008) A New Compression-Molding Approach Using Unidirectionally Arrayed Chopped Strands. Composites: Part A, 42, 1884-1890. https://doi.org/10.1016/j.compositesa.2008.09.012

[2] Taketa, I., Okabe, T. and Kitano, A. (2009) Strength Improvement in Unidirectional Arrayed Chopped Strands with Interlaminar Toughening. Composites: Part A, 40, 1174-1178. https://doi.org/10.1016/j.compositesa.2009.05.006

[3] Yashiro, S. and Ogi, K. (2009) Fracture Behavior in CFRP Cross-Ply Laminates with Initially Cut Fibers. Composites: Part A, 40, 938-947. https://doi.org/10.1016/j.compositesa.2009.04.023

[4] Taketa, I., Sato, N., Kitano, A., Nishikawa, M. and Okabe, T. (2010) Enhancement of Strength and Uniformity in Unidirectionally Arrayed Chopped Strands with Angled Slits. Composites: Part A, 41, 1639-1646. https://doi.org/10.1016/j.compositesa.2010.07.010

[5] Taketa, I., Okabe, H., Matsutani, H. and Kitano, A. (2011) Flowability of Unidirectionally Arrayed Chopped Strands in Compression Molding. Composites: Part B, 42, 1764-1769. https://doi.org/10.1016/j.compositesb.2011.01.021

[6] Li, H., Wang, W.X., Takao, Y. and Matsubara, T. (2013) New Designs of Unidirectionally Arrayed Chopped Strands by Introducing Discontinuous Angled Slits into Prepreg. Com- 
posites: Part A, 45, 127-133. https://doi.org/10.1016/j.compositesa.2012.09.009

[7] Li, H., Wang, W.X. and Matsubara, T. (2014) Multiscale Analysis of Damage Progression in Newly Designed UACS Laminates. Composites: Part A, 57, 108-117. https://doi.org/10.1016/j.compositesa.2013.11.003

[8] O’Higgins, R.M., McCarthy, M.A. and McCarthy, C.T. (2008) Comparison of Open Hole Tension Characteristics of High Strength Glass and Carbon Fibre-Reinforced Composite Materials. Composites Science and Technology, 68, 2770-2778. https://doi.org/10.1016/j.compscitech.2008.06.003

[9] Mall, S., Katwyk, D.W., Bolick, R.L., Kelkar, A.D. and Davis, D.C. (2009) Tension-Compression Fatigue Behavior of a H-VARTM Manufactured Unnotched and Notched Carbon/ Epoxy Composite. Composite Structures, 90, 201-207. https://doi.org/10.1016/j.compstruct.2009.03.015

[10] Yashiro, S. and Okabe, T. (2011) Estimation of Fatigue Damage in Holed Composite Laminates Using an Embedded FBG Sensor. Composites. Part A, 42, 1962-1969. https://doi.org/10.1016/j.compositesa.2011.08.021

[11] Kawai, M. and Shiratsuchi, T. (2012) Vanishing Notch Sensitivity Approach to Fatigue Life Prediction of Notched Cross-Ply CFRP Laminates at Room Temperature. Journal of Composites Materials, 46, 2935-2950. https://doi.org/10.1177/0021998311434790

[12] Fujita, Y., Matsutani, H., Kawamoto, S., Takehara, T. and Taketa, I. (2014) Mechanical Property and Flowability of Quasi-Isotropic UACS Laminates. Proceedings of the $16^{\text {th }} \mathrm{Eu}$ ropean Conference on Composite Materials, Seville, 22-26 June 2004.

\section{Submit or recommend next manuscript to SCIRP and we will provide best service for you:}

Accepting pre-submission inquiries through Email, Facebook, LinkedIn, Twitter, etc. A wide selection of journals (inclusive of 9 subjects, more than 200 journals)

Providing 24-hour high-quality service

User-friendly online submission system

Fair and swift peer-review system

Efficient typesetting and proofreading procedure

Display of the result of downloads and visits, as well as the number of cited articles

Maximum dissemination of your research work

Submit your manuscript at: http://papersubmission.scirp.org/

Or contact ojcm@scirp.org 